\title{
Estimating number of shells and determining the log mean temperature difference correction factor of shell and tube heat exchangers
}

\author{
S. K. Bhatti ${ }^{1}$, Ch. M. Krishna ${ }^{2}$, Ch. Vundru ${ }^{3}$, M. L. Neelapu ${ }^{4}$ \\ \& I. N. Niranjan Kumar ${ }^{5}$ \\ Department of Mechanical and Marine Engineering, Andhra University, \\ Visakhapatnam, India
}

\begin{abstract}
This problem aims at developing a practical and computational tool for LMTD Correction Factor ' $F$ ' and approximate number of shells in the process of designing a shell and tube heat exchanger.

In order to analyze the performance of heat exchanger the available approaches are LMTD and effectiveness $\varepsilon$. Since the expressions for Log Mean Temperature Difference (LMTD) Correction Factor ' $F$ ' are difficult to evaluate, the traditional analysis methods rely on the heat exchanger charts. Apart from being applicable only to a particular heat exchanger, these charts are highly nonlinear and expressed in terms of the non-dimensional parameters $\mathrm{P}$ and $\mathrm{R}$. The LMTD correction factor ' $F$ ' charts are particularly difficult to read in the steep regions. In this study, a simplified analytical approach for determining LMTD correction factor ' $\mathrm{F}$ ' in terms of two non-dimensional parameters $\mathrm{W}$ and $\mathrm{R}$ is presented. This new approach results in a single general algebraic equation for determining the LMTD correction factor of multi-pass shell and tube heat exchangers with any number of shell passes and even number of tube passes per shell. The correction factor thus obtained is a function of number of shells $\mathrm{N}$ and terminal temperatures of the heat exchanger. The value of ' $F$ ' obtained from this new equation is in agreement with the value obtained from the graph.

For a given correction factor ' $F$ ' and terminal temperatures of the heat exchanger, an equation for the estimation of number of shells has been derived, which is a function of correction factor ' $\mathrm{F}$ ' and terminal temperatures of the heat exchanger. This eliminates all the former cumbersome iterative methods in which values are to be assumed for some factors.

Keywords: LMTD correction factor, shell and tube heat exchange, multipass heat exchanger.
\end{abstract}




\section{Introduction}

Heat exchangers are the devices to recover heat between two process streams. The use of heat exchangers is extensive in power plants, refrigeration and air-conditioning systems, space applications, chemical, nuclear, petrochemical, cryogenic industries etc., Heat exchangers appear in variety of shapes and sizes. It can be as huge as a power plant condenser transferring hundreds of megawatts of heat or as tiny as an electronic chip cooler which transfers only a few watts of thermal energy.

\subsection{Multi shell and tube heat exchangers}

In this type of exchangers, the fluid flows in the tubes is known as tube side fluid and the other fluid which flows outside of the tubes in a shell is known as shell side fluid. The tube bundle is arranged inside the shell. To make shell side fluid flow at a higher turbulence and to induce higher heat transfer, baffles are placed in the shell. In order to increase the heat exchange rate between two streams, industries generally use multi shell heat exchangers. If more than one shell is used in a heat exchanger it is called a multi shell heat exchanger. Shell fluid enters the shell, flows across the tube bundle and leaves the shell. This may not serve the purpose of transferring large quantity of heat. But it can be possible in single shell heat exchanger either by increasing the length of the tubes or by increasing the number of tubes. Both the above arrangements are not practically possible due to higher-pressure drops and cost problems. In the multi shell and tube exchangers the shells are connected either in series or in parallel. Fluid enters the shell flows across it and enters into the next shell. The flow conditions are neither parallel flow nor counter flow type. In these exchangers flow is a combination of both parallel and counter flow types. Hence a correction factor ' $F$ ' must be introduced in the general heat equation and the equation is modified as $\mathrm{Q}=\mathrm{UA}(\mathrm{F}) \mathrm{LMTD}$. This correction factor ' $\mathrm{F}$ ' depends on the number of shells of the heat exchanger and on the terminal temperatures of the heat exchanger.

As far as design aspects of heat exchanger are considered, the number of shells in a multi shell-pass heat exchanger is having prime importance. For a given design correction factor $\mathrm{F}$, one has to estimate the number of shells in order to compute the required amount of heat transfer. So far some iterative methods are available for the estimation of number of shells, which are very laborious methods. Over all heat transfer coefficient ' $U$ ' can be estimated from correlated heat transfer coefficients and LMTD is calculated from terminal temperatures of the heat exchanger. But LMTD obtained from terminal temperatures in case of multi pass heat exchangers will not give true temperature difference. Hence to determine the actual mean temperature difference the LMTD of a counter flow heat exchanger with the same terminal temperatures as those of the exchanger under consideration is multiplied by a correction factor, $\mathrm{F} \leq 1$. It provides the effective temperature difference of the heat exchanger under consideration. It is a measure of heat exchanger's departure from the ideal 
behaviour of a counter flow heat exchanger having the same terminal temperatures.

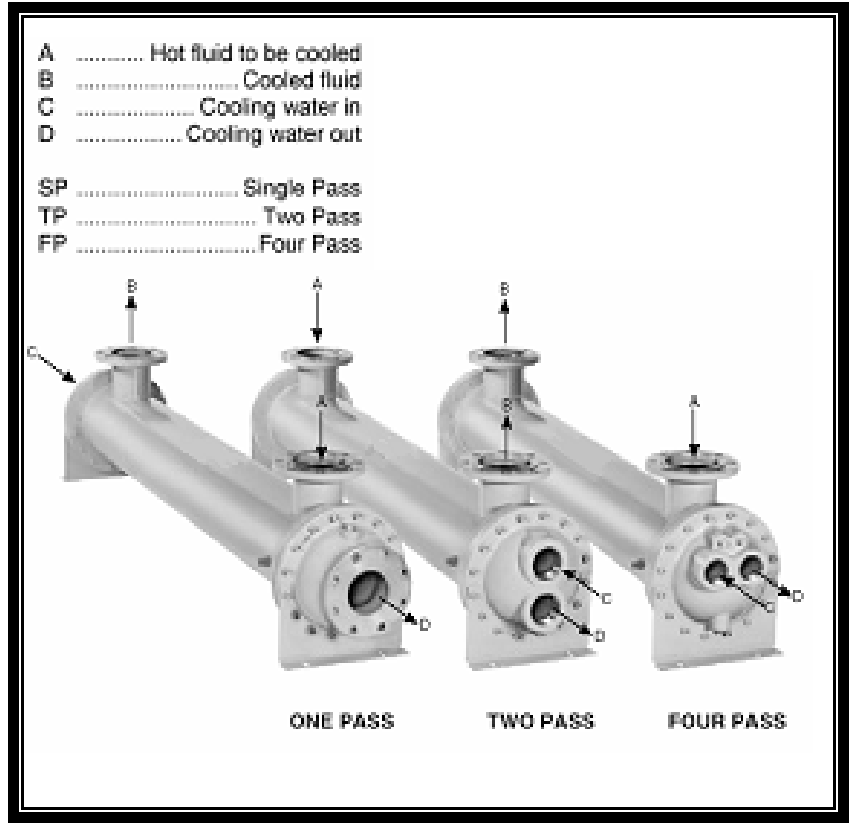

Figure 1: Shell and tube heat exchanger.

\section{Theory}

Wide literature is available on the calculation of Log Mean Temperature Difference correction factor used in the analysis of heat exchangers.

Bowman et al. [2] in their pioneering paper compiled the available data, and presented a series of equations and charts to determine $\mathrm{F}$ for different heat exchangers, including multi-shell and tube ones. They expressed the correction factor $\mathrm{F}$, in terms of two non-dimensional variables $\mathrm{P}$ and $\mathrm{R}$ which are defined as

$$
P=\frac{t_{2}-t_{1}}{T_{1}-t_{1}} \text { and } R=\frac{T_{1}-T_{2}}{t_{2}-t_{1}}
$$

They provided equations for correction factor $\mathrm{F}$, for one shell-two tube pass exchanger and two-shell - four tube pass exchanger. They also provided charts for determining the correction factor for two, four, six shell passes and multiple of tube passes. They have given an equation to calculate $\mathrm{P}$ for an $\mathrm{N}$ shell-side and $2 \mathrm{~N}$ tube-side passes $\left(\mathrm{P}_{\mathrm{N}, 2 \mathrm{~N}}\right)$ in terms of $\mathrm{P}$ for a one-shell-side and two-tube side passes $\left(\mathrm{P}_{1,2}\right)$ and $\mathrm{R}$.

Fakheri [3] in his recent paper introduced two new non-dimensional variables, which are defined as 


$$
\rho=\frac{\mathrm{T}_{1}-\mathrm{t}_{2}}{\mathrm{~T}_{2}-\mathrm{t}_{1}} \quad \phi=\frac{\sqrt{\left(\mathrm{T}_{1}-\mathrm{T}_{2}\right)^{2}}+\sqrt{\left(\mathrm{t}_{2}-\mathrm{t}_{1}\right)^{2}}}{2\left[\left(\mathrm{~T}_{1}+\mathrm{T}_{2}\right)-\left(\mathrm{t}_{1}+\mathrm{t}_{2}\right)\right]}
$$

He used these two variables for heat exchanger analysis and presented correlations for the determination of $\mathrm{F}$ in these two parameters for single shell and tube heat exchanger.

Kern [10] provides correction factor charts for different number of shells and even number of tube passes. He presented the correction factor $\mathrm{F}$, as a function of two variables $\mathrm{R}$ and $\mathrm{S}$, which depends on the inlet and exit temperatures of the heat exchanger of both the fluids.

Roetzel and Nicole [11] recognized the potential usefulness of explicit representations of LMTD Correction factors in developing computerized packages for heat exchanger design.

Taborek [12] interpreted the above parameters $\mathrm{P}$ and $\mathrm{R}$ as the capacity ratio and a measure of heat exchanger effectiveness respectively.

Tucker [13] recently discovered an error in one of the charts for cross flow heat exchangers correction factor. He found for a cross flow heat exchanger with a capacity ratio of unity $(\mathrm{R}=1)$ and $\mathrm{P}=0.6$ the $\mathrm{LMTD}$ correction factor $\mathrm{F}$ read off the chart is 3 percent and extreme combination of low values of $R$ and values of $\mathrm{P}$ approaching unity the error is considerably greater.

Wales [14] defined correction factor by introducing a new parameter $G$ as

$$
\mathrm{G}=\frac{\mathrm{T}_{2}-\mathrm{t}_{2}}{\mathrm{~T}_{1}-\mathrm{t}_{1}}
$$

and expressed $\mathrm{F}$ as a function of $\mathrm{G}$ and $\mathrm{R}$.

\section{Analysis for the determination of LMTD correction factor}

Bowman et al. [2] developed an equation to determine correction Factor ' $F$ ', for 2 shell and 4 tube pass heat exchanger, Besides that they also presented series of charts for the determination of the correction factors for various arrangements of shell and even number of tube passes. To express F, they have chosen two nondimensional variables,

$$
P=\frac{t_{2}-t_{1}}{T_{1}-t_{1}} \quad \text { and } \quad R=\frac{T_{1}-T_{2}}{t_{2}-t_{1}}
$$

The above two variables are interpreted as the capacity ratio and a measure of heat exchanger effectiveness. Reading of charts for the determination of $\mathrm{F}$, particularly in the steep regions of the curves reduces the accuracy.

The present analysis is to derive a single expression for the determination of correction factor $\mathrm{F}$, for any shell and multiple of tube passes.

The breakthrough paper by Bowman et al. [2] provided the following expression to determine the correction factor for shell and tube heat exchangers with one shell and two tube pass exchangers as 


$$
\begin{gathered}
\mathrm{F}_{1-2}=\frac{\sqrt{\mathrm{R}^{2}+1}}{(\mathrm{R}-1)} \frac{\ln \left(\frac{1-\mathrm{P}_{1,2}}{1-\mathrm{P}_{1,2} \mathrm{R}}\right)}{\ln \left(\frac{\frac{2}{\mathrm{P}_{1,2}}-1-\mathrm{R}+\sqrt{\mathrm{R}^{2}+1}}{\frac{2}{\mathrm{P}_{1,2}}-1-\mathrm{R}-\sqrt{\mathrm{R}^{2}+1}}\right)} \\
\mathrm{F}_{2-4}= \\
\frac{\sqrt{\mathrm{R}^{2}+1}}{2(\mathrm{R}-1)} \frac{\ln \left(\frac{1-\mathrm{P}_{2,4}}{1-\mathrm{P}_{2,4} \mathrm{R}}\right)}{\ln \left(\frac{\frac{2}{\mathrm{P}_{2,4}}-1-\mathrm{R}+\frac{2}{\mathrm{P}_{2,4}} \sqrt{\left(1-\mathrm{P}_{2,4}\right)\left(1-\mathrm{P}_{2,4} \mathrm{R}\right)}+\sqrt{\mathrm{R}^{2}+1}}{\frac{2}{\mathrm{P}_{2,4}}-1-\mathrm{R}+\frac{2}{\mathrm{P}_{2,4}} \sqrt{\left(1-\mathrm{P}_{2,4}\right)\left(1-\mathrm{P}_{2,4} \mathrm{R}\right)}-\sqrt{\mathrm{R}^{2}+1}}\right)}
\end{gathered}
$$

Bowman et al. [2] also showed that Eq. (3.1) can also be used for $\mathrm{N}$ shell $2 \mathrm{~N}$ tube pass exchanger provided $\mathrm{P}_{1,2}$ is related to the $\mathrm{P}$ for a multi-shell multi-tube heat exchanger $\left(\mathrm{P}_{\mathrm{N}, 2 \mathrm{~N}}\right)$ by the following expression.

$$
\mathrm{P}_{\mathrm{N}, 2 \mathrm{~N}}=\frac{1-\left[\frac{1-\mathrm{P}_{1,2} \mathrm{R}}{1-\mathrm{P}_{1,2}}\right]^{\mathrm{N}}}{\mathrm{R}-\left[\frac{1-\mathrm{P}_{1,2} \mathrm{R}}{1-\mathrm{P}_{1,2}}\right]^{\mathrm{N}}}
$$

By rearranging the Eq. (3.2)

$$
\left[\frac{1-\mathrm{P}_{1,2} \mathrm{R}}{1-\mathrm{P}_{1,2}}\right]^{\mathrm{N}}=\left[\frac{1-\mathrm{P}_{\mathrm{N}, 2 \mathrm{~N}} \mathrm{R}}{1-\mathrm{P}_{\mathrm{N}, 2 \mathrm{~N}}}\right]
$$

Solving for $\mathrm{P}_{1,2}$

$$
P_{1,2}=\frac{1-\left[\frac{1-P_{N, 2 N} R}{1-P_{N, 2 N}}\right]^{1 / N}}{R-\left[\frac{1-P_{N, 2 N} R}{1-P_{N, 2 N}}\right]^{1 / N}}
$$

Substituting Eq. (3.4) into Eq. (3.1) and after simplification

$\mathrm{F}_{\mathrm{N}, 2 \mathrm{~N}}=$

$$
\frac{\frac{\sqrt{\mathrm{R}^{2}+1}}{\mathrm{R}-1} \ln \left[\frac{1-\mathrm{P}_{\mathrm{N}, 2 \mathrm{~N}} \mathrm{R}}{1-\mathrm{P}_{\mathrm{N}, 2 \mathrm{~N}}}\right]^{1 / \mathrm{N}}}{\ln \left[\frac{1+\left[\frac{1-\mathrm{P}_{\mathrm{N}, 2 \mathrm{~N}} \mathrm{R}}{1-\mathrm{P}_{\mathrm{N}, 2 \mathrm{~N}}}\right]^{1 / \mathrm{N}}-\frac{\sqrt{\mathrm{R}^{2}+1}}{\mathrm{R}-1}+\frac{\sqrt{\mathrm{R}^{2}+1}}{\mathrm{R}-1}\left[\frac{1-\mathrm{P}_{\mathrm{N}, 2 \mathrm{~N}} \mathrm{R}}{1-\mathrm{P}_{\mathrm{N}, 2 \mathrm{~N}}}\right]^{1 / \mathrm{N}}}{\left.1+\left[\frac{1-\mathrm{P}_{\mathrm{N}, 2 \mathrm{~N}} \mathrm{R}}{1-\mathrm{P}_{\mathrm{N}, 2 \mathrm{~N}}}\right]^{1 / \mathrm{N}}+\frac{\sqrt{\mathrm{R}^{2}+1}}{\mathrm{R}-1}-\frac{\sqrt{\mathrm{R}^{2}+1}}{\mathrm{R}-1}\left[\frac{1-\mathrm{P}_{\mathrm{N}, 2 \mathrm{~N}} \mathrm{R}}{1-\mathrm{P}_{\mathrm{N}, 2 \mathrm{~N}}}\right]^{1 / \mathrm{N}}\right]}\right.}
$$


Substituting $\mathrm{W}$ of Eq. (3.6) in place of $\frac{1-\mathrm{P}_{\mathrm{N}, 2 \mathrm{~N}} \mathrm{R}}{1-\mathrm{P}_{\mathrm{N}, 2 \mathrm{~N}}}$

$$
\mathrm{F}_{\mathrm{N}, 2 \mathrm{~N}}=\frac{\Gamma \ln [\mathrm{W}]^{1 / \mathrm{N}}}{\ln \left[\frac{1+[\mathrm{W}]^{1 / \mathrm{N}}-\Gamma+\Gamma[\mathrm{W}]^{1 / \mathrm{N}}}{1+[\mathrm{W}]^{1 / \mathrm{N}}+\Gamma-\Gamma[\mathrm{W}]^{1 / \mathrm{N}}}\right]}
$$

Eq. (3.7) is used to determine the LMTD correction factor in case $\mathrm{N}$ shells $2 \mathrm{~N}$ tube pass heat exchanger. The correction factor is a function of two variables W, $\Gamma$ which are in turn functions of the terminal temperatures of the heat exchanger.

Special Case For $\mathrm{R}=1 \mathrm{Eq}$. (3.1) becomes indeterminate.

$$
\begin{aligned}
& \operatorname{Lim}_{R \rightarrow 1} F_{1-2} \\
& =\operatorname{Lim}_{\mathrm{R} \rightarrow 1} \frac{\sqrt{\mathrm{R}^{2}+1}}{\ln \left(\frac{\frac{2}{\mathrm{P}_{1,2}}-1-\mathrm{R}+\sqrt{\mathrm{R}^{2}+1}}{\frac{2}{\mathrm{P}_{1,2}}-1-\mathrm{R}-\sqrt{\mathrm{R}^{2}+1}}\right)} \times \operatorname{Lim} \frac{\ln \left(\frac{1-\mathrm{P}_{1,2}}{1-\mathrm{P}_{1,2} \mathrm{R}}\right)}{(\mathrm{R}-1)} \\
& \mathrm{F}_{1,2}=\frac{\sqrt{2} \frac{\mathrm{P}_{1,2}}{\left(1-\mathrm{P}_{1,2}\right)}}{\ln \left(\frac{\frac{2}{\mathrm{P}_{1,2}}-2+\sqrt{2}}{\frac{2}{\mathrm{P}_{1,2}}-2-\sqrt{2}}\right)}
\end{aligned}
$$

By rearranging Eq. (3.2)

$$
\begin{gathered}
P_{N, 2 N}=\frac{\left(1-P_{1,2}\right)^{N}-\left(1-P_{1,2} R\right)^{N}}{R\left(1-P_{1,2}\right)^{N}-\left(1-P_{1,2} R\right)^{N}} \\
\operatorname{Lim}_{R \rightarrow 1} P_{N, 2 N}=\operatorname{Lim}_{R \rightarrow 1} \frac{\left(1-P_{1,2}\right)^{N}-\left(1-P_{1,2} R\right)^{N}}{R\left(1-P_{1,2}\right)^{N}-\left(1-P_{1,2} R\right)^{N}} \\
P_{N, 2 N}=\frac{N\left(P_{1,2}\right)}{\left(1-P_{1,2}\right)+N\left(P_{1,2}\right)} \\
P_{1,2}=\frac{P_{N .2 N}}{N-N_{N, 2 N}+P_{N, 2 N}}
\end{gathered}
$$


By substituting Eq. (3.9) into Eq. (3.1)

$$
\begin{gathered}
\mathrm{F}_{\mathrm{N}, 2 \mathrm{~N}}=\sqrt{2} \frac{\mathrm{P}_{\mathrm{N}, 2 \mathrm{~N}}}{\mathrm{~N}-\mathrm{NP}_{\mathrm{N}, 2 \mathrm{~N}}} \frac{1}{\ln \left[\frac{\left[\frac{\mathrm{N}-\mathrm{NP}_{\mathrm{N}, 2 \mathrm{~N}}}{\mathrm{P}_{\mathrm{N}, 2 \mathrm{~N}}}\right]+\frac{1}{\sqrt{2}}}{\left.\left[\frac{\mathrm{N}-\mathrm{NP}_{\mathrm{N}, 2 \mathrm{~N}}}{\mathrm{P}_{\mathrm{N}, 2 \mathrm{~N}}}\right]-\frac{1}{\sqrt{2}}\right]}\right.} \\
\mathrm{F}_{\mathrm{N}, 2 \mathrm{~N}}=\sqrt{2} \mathrm{~W}^{1} \frac{1}{\ln \left[\frac{\frac{1}{\mathrm{~W}^{1}}+\frac{1}{\sqrt{2}}}{\left.\frac{1}{\mathrm{~W}^{1}}-\frac{1}{\sqrt{2}}\right]}\right.}
\end{gathered}
$$

\section{Analysis for the determination of number of shells}

Industries require multi shell heat exchangers in order to carry out the required heat transfer processes. The designer has to design a heat exchanger for a specified design value of ' $F$ '. When multi shell arrangements are necessary it requires estimating the number of shells that are required. Several methods are available so far for determining the number of shells. But all these are iterative methods and values are to be assumed for some factors. To select the values for these factors there is no definite criterion.

Traditionally a tedious trial and error procedure is used in which number of shells is changed continuously and a new F value is determined until a required solution is arrived at.

Ahmad et al. [1] gave an analytical expression for calculating the number of shells directly.

$$
N=\frac{\ln \left[\frac{1-P R}{1-P}\right]}{\ln \left[\frac{R+1+\sqrt{R^{2}-1}-2 R X_{P}}{R+1+\sqrt{R^{2}-1}-2 X_{P}}\right]}
$$

In using Eq. (4.1) the designer has to assume a value for $X_{p}$ to determine number of shells. Then $F$ can be determined and $X_{p}$ should be modified to get the required value of $\mathrm{F}$, in an iterative process.

Gulyani [6] proposed another equation to determine number of shells. $\mathrm{He}$ used another parameter Y.

$$
\mathrm{N}=\frac{\ln \left[\frac{1-\mathrm{GR}}{1-\mathrm{G}}\right]}{\ln \left[\frac{\sqrt{\mathrm{R}^{2}+1}(\mathrm{R}+1-\mathrm{RY})-(\mathrm{R}+1)(\mathrm{R}-1-\mathrm{RY})}{\sqrt{\mathrm{R}^{2}+1}(\mathrm{R}+1-\mathrm{Y})-(\mathrm{R}+1)(\mathrm{R}-1-\mathrm{Y})}\right]}
$$


In Eq. (4.2) also some value is attributed to ( $\mathrm{Y}$ must be assumed some value) determine the number of shells. In this process also $\mathrm{Y}$ should be changed iteratively to determine the desired F.

Fakheri [4] developed a general expression for determining the correction factor $\mathrm{F}$, in terms of number of shells $(\mathrm{N})$ and non-dimensional parameters $\phi, \lambda_{\mathrm{N}}, \lambda_{1}$ which depends on the inlet and exit temperatures of both the fluids. This single expression, which is a simple form, can be used to determine correction factor of multi-pass shell and tube heat exchangers with any number of shell passes and even number of tube passes per shell.

The equation for correction Factor, $F$ developed as

$$
\mathrm{F}=\frac{4 \frac{\phi}{\mathrm{N}} \frac{\lambda_{\mathrm{N}}}{\lambda_{1}}}{\ln \left[\frac{1+2 \frac{\phi}{\mathrm{N}} \frac{\lambda_{\mathrm{N}}}{\lambda_{1}}}{1-2 \frac{\phi}{\mathrm{N}} \frac{\lambda_{\mathrm{N}}}{\lambda_{1}}}\right]} \frac{1}{\lambda_{\mathrm{N}}}
$$

By using Eq. (4.3) an approximate expression for the determination of number of shells can be arrived without using iterative method. Equation for number of shells: Eq. (4.3) can be rearranged as

$$
\lambda_{\mathrm{N}} \mathrm{F}=\frac{4 \frac{\phi}{\mathrm{N}} \frac{\lambda_{\mathrm{N}}}{\lambda_{1}}}{\ln \left[\frac{1+2 \frac{\phi}{\mathrm{N}} \frac{\lambda_{\mathrm{N}}}{\lambda_{1}}}{1-2 \frac{\phi}{\mathrm{N}} \frac{\lambda_{\mathrm{N}}}{\lambda_{1}}}\right]}
$$

By replacing $2 \frac{\phi}{N} \frac{\lambda_{N}}{\lambda_{1}}$ of Eq. (4.4) by K

(Assuming $2 \frac{\phi}{\mathrm{N}} \frac{\lambda_{\mathrm{N}}}{\lambda_{1}} \leq 1$ ) and using Taylor's series of $\ln \left(\frac{1+\mathrm{K}}{1-\mathrm{K}}\right)$

$$
15+5 \mathrm{~K}^{2}+3 \mathrm{~K}^{4}=\frac{15}{\lambda_{\mathrm{N}} \mathrm{F}}
$$

By converting Eq. (4.5) into polynomial form

$$
5\left[1-\frac{1}{\lambda_{\mathrm{N}} \mathrm{F}}\right]+\frac{5}{3} \mathrm{~K}^{2}+\mathrm{K}^{4}=0
$$

This equation has two imaginary and two real roots.

The real roots are:

$$
2 \frac{\phi}{N} \frac{\lambda_{N}}{\lambda_{1}}= \pm \sqrt{-\frac{5}{6}+\sqrt{\frac{25}{36}-5\left[1-\frac{1}{\lambda_{N} \mathrm{~F}}\right]}}
$$

Leaving negative sign, as $\mathrm{K}$ is positive. 
By rearranging the terms of Eq. (4.7) on condition that the values in the square root are positive results that $\mathrm{F} \leq 1.125$

$$
\mathrm{N}=\frac{\phi\left[\frac{\lambda_{\mathrm{N}}}{\lambda_{1}}\right]}{\sqrt{\sqrt{\left[-\frac{155}{576}+\frac{5}{16 \lambda_{\mathrm{N}} \mathrm{F}}\right]}-\frac{5}{24}}}
$$

By using Eq. (4.8), $\mathrm{N}$ can be calculated for the given design value of $\mathrm{F}, \phi$ can be calculated from terminal temperatures of the heat exchanger if

- If the resultant $N \geq 2 \phi$

- If $\mathrm{F} \leq 1.125$ which is always true.

The value calculated from Eq. (4.8 rounded to the nearest integer will give the number of shells for the specified correction factor.

Eq. (4.8) is a direct and simple expression to determine the number of shells in a multi-shell tube heat exchanger. This equation avoids earlier iterative methods for the determination of number of shells to meet the design correction factor for a multi-shell tube heat exchanger.

\section{Results and discussion}

By considering the equations given in reference [2], a simplified expression for the correction factor $\mathrm{F}$, in terms of non-dimensional parameters $\mathrm{W}, \Gamma$ and number of shells $\mathrm{N}$ of the heat exchanger has been given through mathematical analysis. This expression can be used accurately to determine the correction factor F, for heat exchanger having any number of shells. So far, expressions for determining the correction factor for one shell and two shell heat exchangers are available. But, for heat exchangers having more than two shells only charts are available. Charts are also drawn for heat exchangers having different shells. The correction factors obtained are almost equal to the values given in reference [2]. Comparison of results obtained from the new expression against the previous expression:

$$
\begin{aligned}
& \text { For } \mathrm{P}=0.32, \mathrm{R}=3 \\
& \mathrm{~F}_{2-4}=0.56085 \text { (using equation (3.2)) } \\
& \mathrm{F}_{2-4}=0.56057 \text { (using equation (3.7)) } \\
& \mathrm{F}_{\text {For } \mathrm{P}=0.7 \text { and } \mathrm{R}=1.2} \\
& \mathrm{~F}_{4-8}=0.8599 \text { (using equation (3.2)) } \\
& \mathrm{F}_{4-8=}=0.86 \text { (using equation (3.7)) }
\end{aligned}
$$

The errors between the two values are negligible. From the above two comparisons, the new expression obtained in the present work is in agreement with graphs which are already existing in the literature. Hence a single expression is sufficient for any number of shells of the heat exchanger.

Using this new expression for $\mathrm{N}$ the designer can estimate number of shells by adjusting the value obtained to its nearest integer. 


\section{Conclusions}

In this study, a new expression for determining Log Mean Temperature Difference Correction Factor F, in terms of two non-dimensional parameters $\mathrm{P}, \mathrm{R}$ has been analyzed. This new expression presents a single equation to find out the correction factor F, exactly for any number of shells and even number of tube passes. Owing the development of new equation for $F$, reading of $F$ from charts can be avoided. An approximate equation for estimating number of shells for a design value of $\mathrm{F}$ has also been analyzed. This equation avoids earlier iterative methods which are used to determine the number of shells of a multi-shell tube heat exchanger, to meet a given correction factor.

\section{Nomenclature}

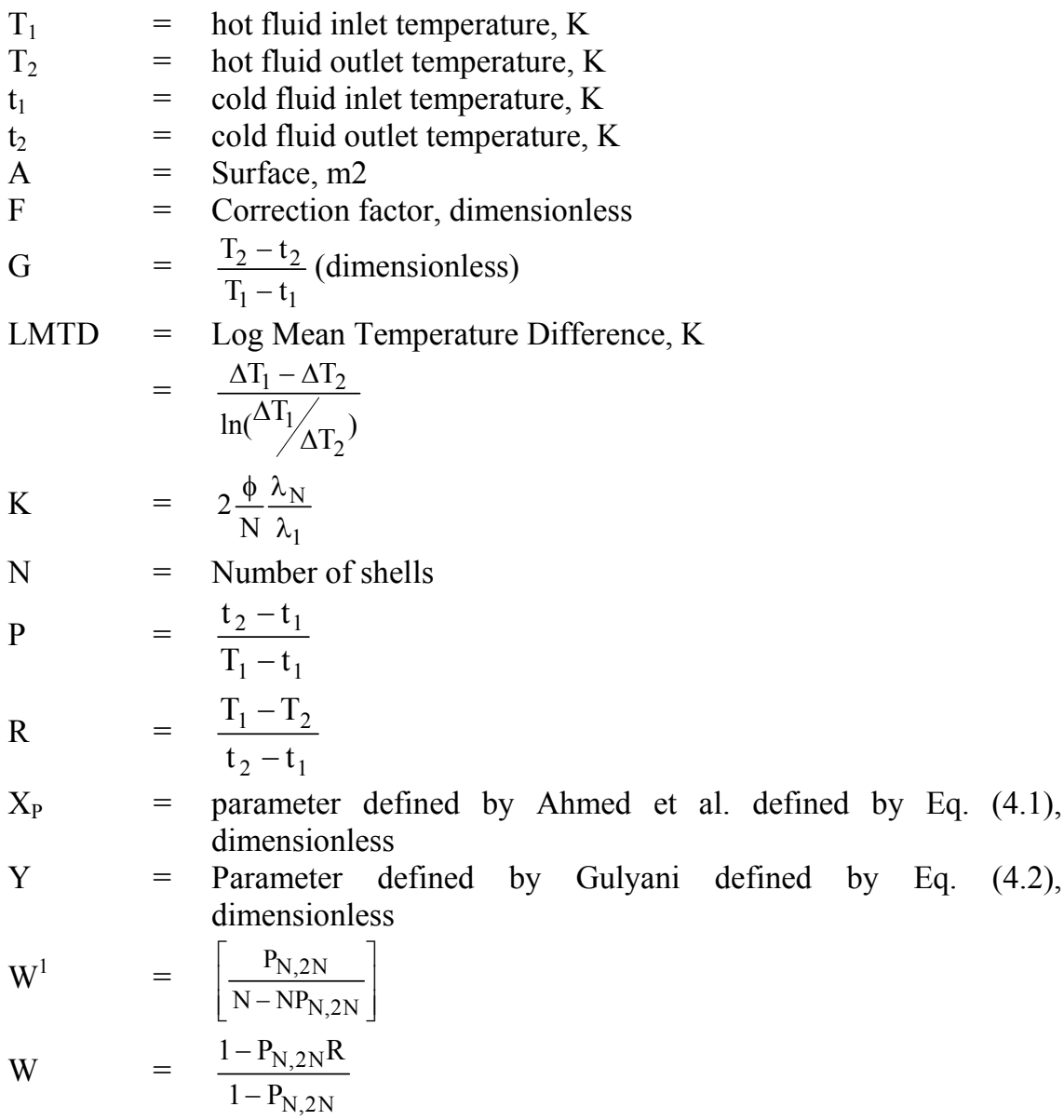


$\Gamma \quad=\frac{\sqrt{R^{2}+1}}{R-1}$

\section{Greek symbols}

$\varepsilon=$ Effectiveness of the heat exchanger

$\phi \quad=\frac{\sqrt{\left(T_{1}-T_{2}\right)^{2}}+\sqrt{\left(t_{2}-t_{1}\right)^{2}}}{2\left[\left(T_{1}+T_{2}\right)-\left(t_{1}+t_{2}\right)\right]}$

$\lambda_{1} \quad=2 \frac{(\rho-1)}{(\rho+1)} \frac{1}{\ln \rho}$

$\lambda_{N} \quad=2 \frac{\left(\rho^{1 / N}-1\right)}{\left(\rho^{1 / N}+1\right)} \frac{1}{\ln \rho^{1 / N}}$

$\rho \quad=\quad \frac{T_{1}-t_{2}}{T_{2}-t_{1}}$

\section{Appendix}

Table 1: Correction factor for a two-shell heat exchanger.

\begin{tabular}{|l|l|l|l|l|l|}
\hline \multicolumn{2}{|l|}{ R=3.0 } & \multicolumn{2}{l|}{ R=1.0 } & \multicolumn{2}{l|}{} \\
\hline P & F & P & F & P.2 & F \\
\hline 0.321 & 0.50 & 0.730 & 0.50 & 0.990 & 0.5 \\
0.320 & 0.56 & 0.600 & 0.89 & 0.980 & 0.71 \\
0.280 & 0.92 & 0.5 & 0.95 & 0.90 & 0.93 \\
0.200 & 0.98 & 0.4 & 0.98 & 0.8 & 0.97 \\
0.150 & 0.99 & 0.3 & 0.99 & 0.5 & 0.99 \\
\hline
\end{tabular}

Table 2: Correction factor for a three-shell heat exchanger.

\begin{tabular}{|l|l|l|l|l|l|}
\hline \multicolumn{2}{|l|}{ R 3 } & \multicolumn{2}{l|}{ R= 1 } & \multicolumn{2}{l|}{ R= 0.4 } \\
\hline $\mathbf{P}$ & F & P & F & P & F \\
\hline 0.332 & 0.5 & 0.825 & 0.5 & 0.986 & 0.5 \\
0.30 & 0.94 & 0.70 & 0.88 & 0.98 & 0.63 \\
0.20 & 0.98 & 0.60 & 0.95 & 0.80 & 0.96 \\
0.16 & 0.99 & 0.49 & 0.99 & 0.60 & 0.99 \\
\hline
\end{tabular}


Table 3: Correction factor for a four-shell heat exchanger.

\begin{tabular}{|l|l|l|l|l|l|}
\hline \multicolumn{2}{|l|}{$\mathbf{R}=\mathbf{2 . 5}$} & \multicolumn{2}{|l|}{$\mathbf{R}=\mathbf{1 . 0}$} & \multicolumn{2}{l|}{} \\
\hline $\mathbf{P}$ & F & P & F & P & F \\
\hline 0.398 & 0.5 & 0.842 & 0.50 & 0.962 & 0.5 \\
0.39 & 0.87 & 0.80 & 0.8 & 0.8 & 0.96 \\
0.30 & 0.98 & 0.66 & 0.96 & 0.7 & 0.98 \\
0.20 & 0.99 & 0.50 & 0.99 & 0.6 & 0.99 \\
\hline
\end{tabular}

Table 4: F values from the expression and from the graph.

\begin{tabular}{|l|l|l|l|l|l|}
\hline \multicolumn{2}{|l|}{$\mathbf{R}=\mathbf{2 . 5}$} & \multicolumn{2}{l|}{$\mathbf{R}$ 1.8 } \\
\hline P & $\begin{array}{l}\text { Calculated } \\
\text { F }\end{array}$ & $\begin{array}{l}\text { From } \\
\text { Graphs }\end{array}$ & P & $\begin{array}{l}\text { Calculated } \\
\text { F }\end{array}$ & $\begin{array}{l}\text { From } \\
\text { Graphs }\end{array}$ \\
\hline 0.3 & 0.948 & 0.93 & 0.4 & 0.9269 & 0.92 \\
0.32 & 0.9345 & 0.92 & 0.43 & 0.91 & 0.88 \\
0.35 & 0.851 & 0.84 & 0.45 & 0.83 & 0.82 \\
0.37 & 0.685 & 0.70 & 0.47 & 0.7527 & 0.75 \\
\hline
\end{tabular}

Table 5: F values from the expression and from the graph.

\begin{tabular}{|l|l|l|l|l|l|}
\hline \multicolumn{2}{|l|}{ R 2.0 } & \multicolumn{2}{l|}{ R 1.6 } \\
\hline P & $\begin{array}{l}\text { Calculated } \\
\text { F }\end{array}$ & $\begin{array}{l}\text { From } \\
\text { Graphs }\end{array}$ & P & $\begin{array}{l}\text { Calculated } \\
\text { F }\end{array}$ & $\begin{array}{l}\text { From } \\
\text { Graphs }\end{array}$ \\
\hline 0.42 & 0.934 & 0.93 & 0.5 & 0.926 & 0.92 \\
0.45 & 0.878 & 0.87 & 0.52 & 0.9 & 0.88 \\
0.46 & 0.842 & 0.85 & 0.55 & 0.832 & 0.82 \\
0.47 & 0.78 & 0.76 & 0.57 & 0.7326 & 0.72 \\
\hline
\end{tabular}

Table 6: F values from the expression and from the graph.

\begin{tabular}{|l|l|l|l|l|l|}
\hline \multicolumn{2}{|l|}{ R = 1.0 } & \multicolumn{2}{l|}{ R =0.8 } \\
\hline P & $\begin{array}{l}\text { Calculated } \\
\text { F }\end{array}$ & $\begin{array}{l}\text { From } \\
\text { Graphs }\end{array}$ & P & $\begin{array}{l}\text { Calculated } \\
\text { F }\end{array}$ & $\begin{array}{l}\text { From } \\
\text { Graphs }\end{array}$ \\
\hline 0.72 & 0.97 & 0.978 & 0.7 & 0.99 & 0.986 \\
0.75 & 0.96 & 0.966 & 0.78 & 0.97 & 0.98 \\
0.8 & 0.91 & 0.93 & 0.82 & 0.96 & 0.97 \\
0.85 & 0.82 & 0.81 & 0.89 & 0.92 & 0.909 \\
\hline
\end{tabular}




\section{References}

[1] Ahmad, S., Linnhoff, B., and Smith, R., "Design of Multi-pass Heat Exchangers: an Alternative Approach", Journal of Heat Transfer, 1988, Vol 110, PP. 304-309.

[2] Bowman, R.A., Mueller, A.C., and Nagel, W.M., "Mean Temperature Difference in Design", Trans. ASME, 1940, Vol. 62, PP.283-294

[3] Fakheri, A., "Log Mean Temperature Correction Factor: An alternative Representation", proceedings of the International Mechanical Engineering Congress and Exposition, 2002, Nov. 17-22.

[4] Fakheri, A., " An alternative approach for determining the log mean temperature difference correction factor and the number of shells of shell and tube heat exchangers", Journal of Enhanced Heat Transfer, 2003, Vol 4, PP.407-420

[5] Gulyani, B.B., and Mohanty, B., "Estimating Log Mean Temperature Difference in Multi-pass Exchangers", Chemical Engineering, 1996, PP. 127-130.

[6] Gulyani, B.B., "Estimating number of shells in shell and tube heat exchangers: A new Approach based on Temperature Cross", Journal of Heat Transfer, 2000, Vol 122, PP. 566-571.

[7] Holman, J.P., "Heat Transfer", Mc Graw-Hill Book Company, 1992.

[8] Incropera, F.P., and David P. DeWitt., "Fundamentals of Heat and Mass Transfer", John and Wiley publishers ISBN: 0-471-38650-2.

[9] Kays, W.M., and London, A.L., "Compact Heat Exchangers", McGrawHill Book Company, 1958.

[10] Kern, D.Q., "Process Heat Transfer”, McGraw - Hill Company,

[11] Roetzel, W., and Nicole, F.J.1., "Mean Temperature Difference for Heat Exchanger Design - A General Approximate Explicit Equation”, Journal of Heat Transfer, 1975, Vol. 97, PP. 5-8.

[12] Taborek, J., "Hand Book of Heat Exchanger Design", Hemisphere, 1990.

[13] Tucker, A.S., "The LMTD Correction Factor for Single-Pass Cross flow Heat Exchangers with Both Fluids Unmixed", Journal of Heat Transfer, 1996, Vol 118, PP. 488-490.

[14] Wales, R.E., "Mean Temperature Difference in Heat Exchangers", Chemical Engineering, 1981, Vol 88, PP. 77-81. 